\title{
A methodological report from the Malmö Diet and Cancer study: development and evaluation of altered routines in dietary data
} processing

\author{
Elisabet Wirfält*1, Irene Mattisson ${ }^{1}$, Ulla Johansson ${ }^{1}$, Bo Gullberg2 , \\ Peter Wallström ${ }^{1}$ and Göran Berglund ${ }^{1}$
}

\author{
Address: ${ }^{1}$ Department of medicine, surgery and orthopaedics, Lund University, University hospital in Malmö, SE-205 02 Malmö, Sweden and \\ 2Department of community medicine, Lund University, University hospital in Malmö, SE-205 02 Malmö, Sweden \\ Email: Elisabet Wirfält* - elisabet.wirfalt@smi.mas.lu.se; Irene Mattisson - irene.mattisson@smi.mas.lu.se; \\ Ulla Johansson - ulla.idun@swipnet.se; Bo Gullberg - bo.gullberg@smi.mas.lu.se; Peter Wallström - peter.wallstrom@smi.mas.lu.se; \\ Göran Berglund - goran.berglund@medforsk.mas.lu.se \\ * Corresponding author
}

Published: 19 November 2002

Nutrition Journal 2002, I:3
Received: 16 September 2002

Accepted: 19 November 2002

This article is available from: http://www.nutritionj.com/content/l/I/3

(c) 2002 Wirfält et al; licensee BioMed Central Ltd. This is an Open Access article: verbatim copying and redistribution of this article are permitted in all media for any purpose, provided this notice is preserved along with the article's original URL.

\begin{abstract}
Background: In the Malmö Diet and Cancer study, information on dietary habits was obtained through a modified diet history method, combining a 7-day menu book for cooked meals and a diet questionnaire for foods with low day-to-day variation. Half way through the baseline data collection, a change of interview routines was implemented in order to reduce interview time.

Methods: Changes concentrated on portion-size estimation and recipe coding of mixed dishes reported in the menu book. All method development and tests were carefully monitored, based on experiential knowledge, and supplemented with empirical data. A post hoc evaluation study using "real world" data compared observed means of selected dietary variables before and after the alteration of routines handling dietary data, controlling for potential confounders.

Results: These tests suggested that simplified coding rules and standard portion-sizes could be used on a limited number of foods, without distortions of the group mean nutrient intakes, or the participants' ranking. The post hoc evaluation suggested that mean intakes of energy-adjusted fat were higher after the change in routines. The impact appeared greater in women than in men.

Conclusions: Future descriptive studies should consider selecting subsets assessed with either method version to avoid distortion of observed mean intakes. The impact in analytical studies may be small, because method version and diet assistant explained less than I percent of total variation. The distribution of cases and non-cases across method versions should be monitored.
\end{abstract}

\section{Background}

Diet history methods are interviewer administered quantitative diet methods which typically use cross-check frequency lists to estimate usual food consumption frequencies, and photographic aids, food models or household measuring devices to estimate usual portion- sizes $[1,2]$. The assessment methodology is relatively time consuming, and the period of participant accrual will inevitably be long in large-scale studies $[2,3]$. Therefore, variations in interview routines or in changes of dietary data collection procedures over time, could potentially affect observed nutrient intakes. Studies of "usual diet" methods 
have indicated that different portion-size alternatives mainly influence the estimated group mean intakes of energy and nutrients, but have smaller effect on the ability to rank individuals on specific nutrient intakes [4-6]. Differential reports may depend on personal characteristics of study participants like obesity [7-11], socio-economic status [12], education and ethnicity [13], or gender [14]. However, food selection is also known to vary by season [3], and general food consumption trends over long timeperiods are observed in most populations [15-17].

In the Malmö Diet and Cancer (MDC) study, a prospective cohort study in the third largest city of Sweden [18], food habit information was obtained through a modified diet history method $[12,19,20]$. During the six-year baseline examination period, a total of seventeen interviewers conducted the dietary interviews. Several measures were taken to facilitate standardized dietary data collection procedures: a continuous in-service training of interviewers; a computer software for standardized entering and coding of data; an extensive set of coding rules for food items and mixed dishes; and a quality control program of collected data. In the spring of 1993 an unforeseen reduction of grants initiated measures to simplify dietary data collection routines and to make faster interviews possible. The change in routines was preceded by a phase evaluating possible options for simplifying the procedures, and a series of tests to examine the effect of different coding and portion-size alternatives on dietary intakes. Because the total and "real world" effect of the altered routines could not be evaluated prior to change, a separate evaluation project was called for. It is, for instance, plausible that, when implemented in full the altered routines would affect dietary interviewers and study-participants, and subsequently, observed intakes in unpredicted ways. Observed intakes at different points in time, could also depend on factors like characteristics and lifestyle of study-participants, or on the year and season of data collection rather than on the handling of data.

This paper therefore presents two separate studies. Study I describes the method development procedures before routine change. First, the amount of time spent on different parts of the dietary interview, and the contribution of total nutrient intake from the different components of the diet history method was examined. Secondly, a series of tests was conducted using two samples of the MDC study population to examine the effect of different coding and portion-size estimation alternatives on the ability to estimate group mean intakes, and to rank individuals on nutrient intakes. Study II examines MDC baseline data collected before and after the change in routines, and evaluates whether the alteration in handling dietary data influenced the observed mean intakes of selected food- groups and nutrients, independently of lifestyle and characteristics of study-participants.

\section{Methods}

\section{The Malmö Diet and Cancer study}

Population and baseline examinations

The baseline examinations of the MDC study started in March 1991 and ended in October 1996. Eligible participants were men in the age-range 46 to 73 years, and women in the age-range 45 to 73 years, living in the City of Malmö and with Swedish reading and writing skills. When recruitment closed, 28098 persons had completed all baseline examinations. The data collection included dietary habits, socio-economics, medical history, and lifestyle habits using questionnaires and interview. Anthropometrics, body composition, and blood pressure were collected through direct measurements. Blood samples were collected, frozen, and stored for biochemical analysis at a later stage. Participants visited the study centre twice. During the first visit, the study procedures and questionnaires were explained, direct measurements made and blood samples collected. Two weeks later, the questionnaires completed at home were reviewed and the diet history interview conducted.

\section{The modified diet history method}

The modified diet history method of the MDC [19] consisted of a menu book and a diet history questionnaire. In the menu book, participants recorded cooked meals, cold beverages (i.e., milk, juice, soft drinks, water and alcoholic beverages), drugs, natural remedies, and dietary supplements during seven consecutive days. In the diet history questionnaire the general meal pattern and the frequency and portion-size information of foods consumed regularly and with low day-to-day variation (i.e., hot beverages, sandwiches, edible fats, breakfast cereals, yoghurt, milk, fruits, cakes, candies and snacks) were recorded. The reference period of the questionnaire was the preceding year. The choice of methodology was guided by the need to assess total diet in a middle-aged and older urban population where the daily eating habits included cooked meals and mixed dishes. The participant at home estimated the usual portion-sizes of foods reported in the questionnaire from a booklet with 48 black and white photographs. A more extensive book of photographs was used during the dietary interview to estimate usual portion-sizes of dishes and foods in the menu book. During the interview, the questionnaire and the menu book were checked, according to predefined rules, so that reported food consumption did not overlap and were in concordance with the overall meal pattern reported by the participant.

The specific food information obtained from the questionnaire, the menu book and during the diet history interview was coded, entered and converted into nutrient 
intake data by use of the interactive computer software KOSTSVAR (AIVO AB), and the Swedish Food Database PC KOST2-93 of the Swedish National Food Administration. PC KOST2-93 contains approximately 1600 basic foods; additional recipes and food codes were added specifically for the MDC study.

Portion-sizes were estimated with photographic aids during the interview. Typically, a set of 4 photos (A-D), displaying 4 different portion-sizes of the same dish, was shown to the participants. One set of photos was shown for each dish, or food, registered in the menu book. The participants were not limited to the amounts indicated by the photos, but were encouraged to describe their usual portion-sizes as exact as possible. Thus, portion-sizes could be expressed in several ways i. e. "half the size of C", "between B and C", "D plus A" etc. Information on portion-sizes was entered into the computer and converted into grams.

When coding foods and mixed dishes recorded in the menu book, the software guided the interviewer through a system of "recipe identifiers". These specifically helped identify preparation methods and ingredients in mixed dishes. A "recipe identifier" indicating the type of dish (e.g., casserole with meat) was first entered. The following menu on the screen listed potential codes, indicating the specific constituents of different casseroles. The interviewers choose the most appropriate code and made necessary adaptations of the recipe concurrently, depending on the information given by the participant. The MDC method included the option of exchanging a maximum of four ingredients in standard (default) recipes. The ingredient changes focused on the amount and quality of fat (type of dietary fat, liquid in sauces and casseroles, meat, fish) and vegetables. In addition, the MDC method included the option of creating new individual recipes during the dietary interview. This procedure was used (by judgement of the dietary interviewer) when standard recipes, with ingredient exchanges, did not cover the recipe described by the participant.

Extensive in-service training, the interactive computer software with specific coding rules and a continuous quality control program of collected data ensured standardisation of dietary data collection across dietary interviewers. Weekly training sessions and bi-yearly workshops were conducted to discuss and solve problems related to coding and entering of dietary data. In addition, the two head nutritionists (I.M. and U.J.) conducted weekly inspections of questionnaires and menu books (randomly selected from each dietary interviewer), and regularly listened in on dietary interviews. Extreme portion-sizes were identified through a monthly, computerised quality control routine, and were either verified or corrected if erroneous. In addi- tion, the extreme and median values of total energy, all nutrients, and major food groups were regularly inspected, and erroneous values attended to. Finally, the age and gender specific ratios of total energy intake to basal metabolic rate (EI/BMR) was computed [21], using the formula for BMR identified by a joint FAO/WHO/UNU expert consultation [22]. Extreme and median values were identified, and the dietary reports of these individuals were checked for errors.

The concurrent validity of the diet assessment method was previously tested against 18 days of weighed food records, collected during one year, as the reference [12]. The validation study included 241 Malmö residents (126 men and 115 women) in the age range 50-69 years. The energy and nutrient correlations were amongst the highest compared to those found in validation studies of other "usual" diet instruments, performed in other populations [2327].

\section{Study I: Development of new routines to handle dietary data Methods}

Study I describes the development procedures undertaken during the autumn of 1993 and spring of 1994, prior to implementing the change of routines in dietary data handling.

\section{Preparatory phase} Interview time

Six dietary interviewers with long interviewing experience recorded the amount of time required for the different parts of the diet history interview (i.e., information given to participants, general meal pattern, menu book, and diet history questionnaire). The time records were kept during one week in the autumn of 1993 and included interviews with all study-participants $(n=64)$, seen by the six interviewers that week.

Nutrient intakes from the different components of the diet history method

Dietary data from all participants joining the study during 1992 was used to examine the origin of nutrient intake information. Total nutrient intake was first partitioned into intakes estimated from the diet history questionnaire, from the menu book excluding beverages, and from beverages in the menu book. Secondly, the menu book excluding beverages was examined separately, to identify the types of foods and mixed dishes that were the major contributors of specific nutrients. Mixed dishes and foods were aggregated into groups defined by the type of dish (e.g. all sauces in one group). The choice of nutrient variables was guided by (1) the potential relations between foods, nutrients and cancer development described in the literature, and (2) the wish to examine changes in nutri- 
ent-markers of specific food groups (e.g. B12 for meat and eicosapentaenoic acid for fish). The percentage contribution of different food sources in the menu book was calculated for the following nutrients: Total fat, saturated fatty acids (SFA), monounsaturated fatty acids (MUFA), polyunsaturated fatty acids (PUFA), linoleic acid (18:2), $\alpha$-linolenic acid (18:3), eicosapentaenoic acid (EPA), cholesterol, $\beta$-carotene, tocopherol, selenium, dietary fibre, B12, and folic acid.

\section{Tests of different options for reducing interview time Test-samples}

Two samples from the MDC cohort were selected for the testing of interview simplifications. All study participants who joined the study during 1992 (2660 women and 1769 men) and 156 study participants (88 women and 68 men) who joined the study in November and December 1993.

\section{Standard portion-sizes and simplified coding}

Dietary data collected from individuals of the larger sample was used in three steps testing the use of standard portion-sizes and simplified coding. First, median portionsizes were defined, separately for men and women; these were used as "standard portion sizes" in the tests. Secondly, intake data assessed with the original individually estimated portion-sizes were compared with intake data using the standard portion-sizes for a limited number of dishes and foods (see appendix 1). Thirdly, intake data assessed with the original recipe coding (with ingredient exchange options) were compared with intake data obtained with recipes in the default format (standard recipes with no exchanges). These tests focused on recipes that required large time input during coding, and dishes with low nutrient contributions (see appendix 1). Nutrient intake estimates of test data were compared with original data.

The combined effect of simplified coding and standard portion-sizes was finally examined. In the same data set, the individually estimated portion-sizes were converted to standard portion-sizes, and the recipes with exchange options were converted to default recipes. The combined effect was examined by comparing converted data with original data (i.e., data including both individually estimated portion-sizes and exchange of ingredients in recipes).

\section{Fewer portion-size photos and individual recipes}

Individuals of the smaller sample participated in an experiment of using fewer portion-size photos. In this test, one set of photos was selected to represent several foods within a food group (e.g. photos of one type of boiled vegetables for all types of boiled vegetables). The number of photo sets was reduced from 180 to 14 . Participants were asked to select portion-sizes twice: first with to the original, complete photo sets, and then using the reduced number photo sets. In addition, data from the smaller sample were used to examine the effect of not using individual recipes, by re-coding all individual recipes to the "best choice" among the standard recipes in the existing database. The two head nutritionists undertook this recoding procedure after completion of the dietary interviews.

\section{Nutrient variables}

The nutrients examined when testing the effect of different portion-size and coding alternatives were: Total energy (kcal), total fat (g), linoleic acid, 18:2 (g), $\alpha$-linolenic acid, 18:3 (g), eicosapentaenoic acid, EPA (g), tocopherol $(\mathrm{g})$, selenium $(\mu \mathrm{g}), \beta$-carotene $(\mathrm{mg})$, ascorbic acid $(\mathrm{mg})$, dietary fibre $(\mathrm{g})$ and B12 $(\mu \mathrm{g})$.

\section{Statistical tests}

Paired t-tests were used to compare mean nutrient intakes between test data and original data. The effect of changed routines on ranking of individuals was examined with two approaches. First, quintiles of energy and nutrient intakes estimated from the original data were cross-classified against quintiles of the test data. Secondly, correlation analysis was conducted comparing data from the original data with the test data. The Pearson product moment correlation coefficients were calculated for energy and all examined nutrients. In all tests, all variables were logarithm transformed and nutrient intakes were energy-adjusted according to the residual method [28]. Tests with the larger sample of standardised portion-sizes and of simplified coding, were gender specific. In addition, these tests first examined the specific effect of each subset of codes (appendix 1), and secondly, the total effects of all subsets. The combined effect of standard portion-sizes and simplified coding was examined with all subsets of codes.

\section{Results and Discussion}

Preparatory phase

The mean time required for the diet history interview was 65 (SD 8) minutes. Approximately 50 percent of the time was spent on the menu book, 25 percent on the dietary questionnaire and the rest on the meal pattern and on information given to the participants. The menu book (exclusive beverages) contributed approximately 30 percent of total mean intake for most nutrients (see Table 1,2). However, more than 60 percent of the total intake of eicosapentaenoic acid, approximately 50 percent of cholesterol, $\beta$-carotene, and selenium, and almost 50 percent of B12 originated from the menu book. Fish-dishes contributed most to the total intake of eicosapentaenoic acid, while boiled vegetables, salads as side dishes, casseroles, and soups were major contributors of $\beta$-carotene. Dishes 
Table I: Energy and nutrient contributions by major food groups ${ }^{a}$, recorded by women $(n=2660)$ in the menu-book.

\begin{tabular}{|c|c|c|c|c|c|c|c|c|c|c|c|c|c|c|c|}
\hline & Energy & $\begin{array}{c}\text { Total } \\
\text { fat }\end{array}$ & SFA & MUFA & PUFA & $18: 2$ & $18: 3$ & EPA & Cholesterol & $\beta$-carotene & Tocopherol & Selenium & $\begin{array}{l}\text { Dietary } \\
\text { fibre }\end{array}$ & $\mathrm{B} \mid 2$ & $\begin{array}{l}\text { Folic } \\
\text { acid }\end{array}$ \\
\hline $\begin{array}{l}\text { Total } \\
\text { menu-book }\end{array}$ & 29.6 & 34.0 & 29.7 & 38.0 & 36.2 & 33.6 & 35.7 & 65.7 & 51.6 & 57.4 & 34.2 & 57.8 & 27.0 & 47.3 & 33.1 \\
\hline Potatoes & 4.3 & 1.7 & 1.3 & 2.0 & 2.4 & 2.0 & 2.6 & $<1.0$ & $<1.0$ & $<1.0$ & 2.4 & $<1.0$ & 5.7 & $<1.0$ & 3.4 \\
\hline Rice & $<1.0$ & $<1.0$ & $<1.0$ & $<1.0$ & $<1.0$ & $<1.0$ & $<1.0$ & $<1.0$ & $<1.0$ & $<1.0$ & $<1.0$ & 1.1 & 1.2 & $<1.0$ & $<1.0$ \\
\hline Pasta & $<1.0$ & $<1.0$ & $<1.0$ & $<1.0$ & $<1.0$ & $<1.0$ & $<1.0$ & $<1.0$ & $<1.0$ & $<1.0$ & $<1.0$ & $<1.0$ & $<1.0$ & $<1.0$ & $<1.0$ \\
\hline Sauce/gravy & 1.4 & 2.8 & 3.1 & 2.9 & 2.0 & 2.0 & 2.9 & $<1.0$ & 1.2 & $<1.0$ & 2.2 & $<1.0$ & $<1.0$ & $<1.0$ & $<1.0$ \\
\hline Meat & 4.4 & 6.8 & 6.1 & 8.6 & 4.8 & 4.5 & 3.1 & 4.8 & 10.7 & $<1.0$ & 2.7 & 11.8 & $<1.0$ & 17.7 & 2.5 \\
\hline Minced meat & 1.2 & 1.8 & 1.8 & 2.2 & 1.2 & 1.1 & $<1.0$ & $<1.0$ & 2.9 & $<1.0$ & $<1.0$ & 2.2 & $<1.0$ & 1.3 & $<1.0$ \\
\hline Sausage & 1.4 & 2.8 & 2.5 & 3.8 & 1.7 & 1.6 & I.I & $<1.0$ & 2.0 & $<1.0$ & $<1.0$ & $<1.0$ & $<1.0$ & 1.5 & $<1.0$ \\
\hline Fish & 1.5 & 1.8 & I.I & 1.9 & 2.9 & 1.2 & 1.8 & 40.5 & 4.2 & $<1.0$ & 3.7 & 15.6 & $<1.0$ & 10.1 & $<1.0$ \\
\hline $\begin{array}{l}\text { Boiled } \\
\text { vegetables }\end{array}$ & $<1.0$ & $<1.0$ & $<1.0$ & $<1.0$ & $<1.0$ & $<1.0$ & 1.2 & $<1.0$ & $<1.0$ & 14.3 & $<1.0$ & $<1.0$ & 3.1 & $<1.0$ & 4.4 \\
\hline $\begin{array}{l}\text { Salad as side } \\
\text { dish }\end{array}$ & $<1.0$ & $<1.0$ & $<1.0$ & $<1.0$ & 1.4 & 1.6 & 1.5 & $<1.0$ & $<1.0$ & 25.4 & 2.7 & $<1.0$ & 4.0 & $<1.0$ & 7.2 \\
\hline Soups & $<1.0$ & $<1.0$ & $<1.0$ & $<1.0$ & $<1.0$ & $<1.0$ & $<1.0$ & $<1.0$ & $<1.0$ & 4.1 & 1.0 & 1.1 & 1.7 & $<1.0$ & 1.4 \\
\hline Casseroles & 1.8 & 2.2 & 2.2 & 2.6 & 1.7 & 1.5 & 2.9 & 1.6 & 2.5 & 5.7 & 2.3 & 3.2 & 2.6 & 3.8 & 3.2 \\
\hline Desserts & 1.7 & 1.7 & 1.9 & 1.7 & 1.4 & 1.4 & 1.6 & $<1.0$ & 1.4 & $<1.0$ & 2.0 & $<1.0$ & 1.6 & $<1.0$ & $<1.0$ \\
\hline Dressing & $<1.0$ & $<1.0$ & $<1.0$ & $<1.0$ & 3.6 & 4.2 & 2.9 & $<1.0$ & $<1.0$ & $<1.0$ & $<1.0$ & $<1.0$ & $<1.0$ & $<1.0$ & $<1.0$ \\
\hline Egg dishes & $<1.0$ & 1.4 & 1.1 & 1.7 & I.I & 1.0 & 1.1 & $<1.0$ & 8.7 & $<1.0$ & 2.2 & 4.8 & $<1.0$ & 1.5 & $<1.0$ \\
\hline
\end{tabular}

a Food groups contributing less than one percent of energy and most nutrients but more than I.5\% of at least one key nutrient: Cold sauce: I8:23.6\%, 18:3-3.0\%; Smoked fish: EPA-5.1\%, Selenium-1.7\%, BI2-1.7\%; Boiled shellfish: 20:5-1.6; Salad as main dish: Se-1.9\%; Salad with mayonnaise: cholesterol-6.1\%; Gratin: Se-3.2\%, BI2-1.8\% b Excluding beverages

Table 2: Energy and nutrient intake contributions by major food groups ${ }^{\mathrm{a}}$ recorded by men $(\mathrm{n}=1769)$ in the menu-book.

\begin{tabular}{|c|c|c|c|c|c|c|c|c|c|c|c|c|c|c|c|}
\hline & Energy & $\begin{array}{c}\text { Total } \\
\text { fat }\end{array}$ & SFA & MUFA & PUFA & $18: 2$ & $18: 3$ & EPA & Cholesterol & $\beta$-carotene & Tocopherol & Selenium & $\begin{array}{l}\text { Dietary } \\
\text { fibre }\end{array}$ & $\mathrm{B} 12$ & $\begin{array}{l}\text { Folic } \\
\text { acid }\end{array}$ \\
\hline $\begin{array}{l}\text { Total menu } \\
\text { book }^{\mathrm{b}}\end{array}$ & 30.5 & 34.2 & 30.5 & 38.1 & 34.5 & 31.7 & 35.5 & 62.9 & 50.1 & 68.0 & 34.5 & 57.5 & 29.6 & 45.2 & 34.2 \\
\hline Potatoes & 5.6 & 2.4 & 1.8 & 2.8 & 3.1 & 2.7 & 3.7 & $<1.0$ & $<1.0$ & 1.3 & 3.6 & $<1.0$ & 8.1 & $<1.0$ & 5.1 \\
\hline Rice & $<1.0$ & $<1.0$ & $<1.0$ & $<1.0$ & $<1.0$ & $<1.0$ & $<1.0$ & $<1.0$ & $<1.0$ & $<1.0$ & $<1.0$ & 1.2 & 1.3 & $<1.0$ & $<1.0$ \\
\hline Pasta & $<1.0$ & $<1.0$ & $<1.0$ & $<1.0$ & $<1.0$ & $<1.0$ & $<1.0$ & $<1.0$ & $<1.0$ & $<1.0$ & $<1.0$ & $<1.0$ & $<1.0$ & $<1.0$ & $<1.0$ \\
\hline Sauce/gravy & 1.4 & 3.0 & 3.3 & 3.0 & 2.1 & 2.1 & 3.2 & $<1.0$ & 1.3 & $<1.0$ & 2.6 & $<1.0$ & $<1.0$ & $<1.0$ & $<1.0$ \\
\hline Meat & 5.2 & 7.8 & 7.3 & 9.7 & 5.2 & 4.8 & 3.6 & 4.9 & 13.0 & $<1.0$ & 3.4 & 14.3 & $<1.0$ & 18.8 & 3.0 \\
\hline Minced meat & 1.2 & 1.8 & 1.8 & 2.2 & 1.1 & 1.0 & $<1.0$ & $<1.0$ & 3.2 & $<1.0$ & $<1.0$ & 2.4 & $<1.0$ & 1.3 & $<1.0$ \\
\hline Sausage & 1.7 & 3.3 & 1.8 & 2.2 & 1.1 & 1.0 & $<1.0$ & $<1.0$ & 2.6 & $<1.0$ & $<1.0$ & $<1.0$ & $<1.0$ & 1.7 & $<1.0$ \\
\hline Fish & 1.5 & 1.8 & 1.1 & 2.0 & 2.9 & 1.1 & 1.9 & 41.7 & 4.1 & $<1.0$ & 3.8 & 15.4 & $<1.0$ & 9.4 & 1.0 \\
\hline $\begin{array}{l}\text { Boiled vege- } \\
\text { tables }\end{array}$ & $<1.0$ & $<1.0$ & $<1.0$ & $<1.0$ & $<1.0$ & $<1.0$ & $<1.0$ & $<1.0$ & $<1.0$ & 16.2 & $<1.0$ & $<1.0$ & 2.5 & $<1.0$ & 3.6 \\
\hline $\begin{array}{l}\text { Salad as side } \\
\text { dish }\end{array}$ & $<1.0$ & $<1.0$ & $<1.0$ & $<1.0$ & 1.1 & 1.3 & 1.1 & $<1.0$ & $<1.0$ & 28.6 & 2.1 & $<1.0$ & 3.3 & $<1.0$ & 6.1 \\
\hline Soups & $<1.0$ & $<1.0$ & $<1.0$ & $<1.0$ & $<1.0$ & $<1.0$ & $<1.0$ & $<1.0$ & $<1.0$ & 5.6 & $<1.0$ & 1.3 & 2.2 & $<1.0$ & 1.5 \\
\hline Casseroles & 1.9 & 2.2 & 2.1 & 2.5 & 1.7 & 1.5 & 3.0 & 1.1 & 2.7 & 7.9 & 2.3 & 2.9 & 3.3 & 3.7 & 3.9 \\
\hline $\begin{array}{l}\text { Complete } \\
\text { dishes }\end{array}$ & $<1.0$ & $<1.0$ & $<1.0$ & 1.0 & $<1.0$ & $<1.0$ & $<1.0$ & $<1.0$ & 1.2 & $<1.0$ & $<1.0$ & 1.0 & $<1.0$ & $<1.0$ & $<1.0$ \\
\hline Desserts & 1.2 & 1.2 & 1.3 & 1.1 & $<1.0$ & $<1.0$ & 1.1 & $<1.0$ & 1.0 & $<1.0$ & 1.4 & $<1.0$ & 1.3 & $<1.0$ & $<1.0$ \\
\hline Dressing & $<1.0$ & $<1.0$ & $<1.0$ & $<1.0$ & 3.0 & 3.4 & 2.7 & $<1.0$ & $<1.0$ & $<1.0$ & $<1.0$ & $<1.0$ & $<1.0$ & $<1.0$ & $<1.0$ \\
\hline Egg dishes & $<1.0$ & 1.2 & 1.0 & 1.5 & $<1.0$ & $<1.0$ & 1.0 & $<1.0$ & 8.2 & $<1.0$ & 2.0 & 4.6 & $<1.0$ & $<1.0$ & $<1.0$ \\
\hline
\end{tabular}

a Food groups contributing less than one percent of energy and most nutrients but more than $1.5 \%$ of at least one key nutrient: Smoked fish: EPA-4. $1 \%$; Salad as main dish: $\beta$ carotene-1.8\%; Salad with mayonnaise: cholesterol-2,8\%; Gratin: 20:5-2.1\%, Se-3.2\%; Pudding: EPA-2.1\% b Excluding beverages

with meat, fish, or egg contributed most to selenium intakes, and meat and fish dishes to B12.

Tests of different options for reducing interview time

Because handling of dietary information from the menu book, specifically the use of certain portion-size aids and coding routines, proved to be the most time-consuming parts of the dietary interview, these were given priority in method development. Although, the overall intake contribution of the menu book was smaller compared to the diet questionnaire, a concern was raised for some nutrients (from vegetables, meat and fish) of potential impor- 
tance in diet-cancer studies [29]. This concern prompted the extensive testing of the potential changes in dietary data handling.

Because the menu book also contributed substantially to the assessment of important foods and nutrients, the possible interview simplifications were limited to two procedures: portion-size estimation and coding of foods and dishes assessed through the menu book. The results from tests examining the combined effects are presented.

When examining data from the larger sample and the use of standard portion-sizes compared to individual portionsizes, the correlation coefficients were very high, in both men and women, table 3 . The lowest correlation was observed in women for linoleic acid $(r=0.982)$ and $\alpha$-linolenic acid $(r=0.983)$. In cross-classification of corresponding quintiles, the exact agreement was above $90 \%$ for $\beta$-carotene, vitamin $\mathrm{C}$, fibre, and $\mathrm{B} 12$ both in men and women. For energy, $\alpha$-linolenic acid, tocopherol and selenium the agreement was between 85 and 90 percent. Linoleic acid had the lowest exact agreement, 84 percent in women. Crude data had slightly lower agreement in some nutrients, but for most nutrients, the results were the same. Differences in mean intakes of energy and nutrients were significant, original data had slightly higher (i.e., $<2 \%$ for men and $<1 \%$ for women) levels compared to test data (data not shown).

Also, with the larger sample, simplified coding only marginally affected the ranking ability of observed intakes, table 3 . The correlations were very high $(\mathrm{r}>0.990)$ for energy and all nutrients, except $\beta$-carotene, in both gender groups. The exact agreement of corresponding quintiles was well above 90 percent for energy and most nutrients, in both men and women. In women, the exact agreement for $\beta$-carotene was 91 percent, and in men 89 percent. Crude data had slightly (1-2\%) higher agreement. Differences in mean energy and nutrient intakes were overall extremely small, original data had somewhat higher $(<1 \%$ for both men and women) intake levels). Differences were not significant for ascorbic acid in women and for fibre in men (data not shown).

The combined effect of standard portion-sizes and simplified coding showed slightly lower correlations and agreements compared to standard portion-sizes or simplified coding only. Overall correlations were higher than 0.980 , except for linoleic acid in women $(\mathrm{r}=0.972)$. The exact agreement in classification was 85 percent or higher for energy and all nutrients except selenium ( 83 percent in women, 81 percent in men), linoleic acid, and $\alpha$-linolenic acid in women ( 82 and 83 percent), data not shown.
When testing the effect of fewer sets of portion-size pho$\underline{\text { tos, }}$ in the smaller sample, compared to complete sets of photos, the correlations were high $(r>0.950)$ for all nutrients. In cross-classification the exact agreement was between 85 and 90 percent for fibre, eicosapentaenoic acid and $\alpha$-linolenic acid. For most other nutrients, the agreement ranged between 75 and 85 percent, table 4 . The lowest agreement (74 percent) was seen in $\beta$-carotene. Differences in mean intakes of energy, total fat, selenium and fibre were significant but small $(1,5-3,5 \%)$, original data having the highest level (data not shown). Differences in mean intakes of linoleic acid, $\alpha$-linolenic, eicosapentaenoic acid, tocopherol, $\beta$-carotene, ascorbic acid, and B12 were not significant.

When re-coding individual recipes to standard recipes, also with the smaller sample, the observed correlations were extremely high $(\mathrm{r}>0.995)$ for all nutrients, table 4 . The exact agreement of corresponding quintiles was 97 percent or more for most nutrients. For vitamin B12 the exact agreement was 95 percent. No significant differences were seen in mean intakes of energy or in any of the examined nutrients (data not shown).

The influences on dietary intakes, ranking especially, of routine changes was small. Using standardised portionsizes or reduced number of photo sets influenced the observed intakes to a larger extent, than using standard recipes instead of individual recipes or recipes with fewer ingredient exchanges.

Overall, the changes to use of portion-size aids influenced the observed intakes more than changes in coding routines. Since the effect on nutrient intakes was considered to be too large (table 4), the tested reduction of portionsize photo sets was not implemented. The use of standard portion-sizes was accepted, but to a smaller extent than in, the tests performed. For instance, individual portion-sizes were kept for major food sources of polyunsaturated fatty acids and selenium (table 3 ), and for all vegetables to minimise effect on observed intakes. The procedure of creating individual recipes was time consuming. Since the tests showed that removing this procedure only marginally influenced nutrient intakes, this option was removed. The effect of reducing the number of recipes with exchange options was more complex. This option was retained for recipes that were major sources of $\beta$-carotene, total fat and specific fatty acids. When these changes (standard portion-sizes on a limited number of foods, fewer recipes with exchange options, and no individual recipes) were carried through, the number of questions asked during the interview was substantially reduced. Other tasks (i.e., check of the socio-economic questionnaires) were also removed from the dietary interview. No changes were made to the interview routine of the diet his- 
Table 3: Correspondence between the original data and test data when using "Standard portion sizes" and "Simplified coding": Pearson correlation coefficients $(r)$, and percent agreement $(\%)$ in cross-classification, of energy and nutrient estimates, separately for women $(n=2660)$ and $\operatorname{men}(n=1769)$.

\begin{tabular}{|c|c|c|c|c|c|c|c|c|}
\hline \multirow[t]{3}{*}{ Energy and nutrients } & \multicolumn{4}{|c|}{ Standard portion-sizes } & \multicolumn{4}{|c|}{ Simplified coding } \\
\hline & \multicolumn{2}{|c|}{ Women } & \multicolumn{2}{|c|}{ Men } & \multicolumn{2}{|c|}{ Women } & \multicolumn{2}{|c|}{ Men } \\
\hline & $r$ & $\%$ & $r$ & $\%$ & $r$ & $\%$ & $r$ & $\%$ \\
\hline Energya & 0.992 & 88 & 0.989 & 85 & 0.999 & 97 & 0.999 & 98 \\
\hline Total fatb & 0.992 & 90 & 0.992 & 90 & 0.997 & 92 & 0.998 & 94 \\
\hline Linoleic acid ${ }^{\mathrm{b}}$ & 0.982 & 84 & 0.984 & 86 & 0.996 & 94 & 0.997 & 92 \\
\hline$\alpha$ linolenic acidb & 0.983 & 85 & 0.984 & 86 & 0.997 & 93 & 0.998 & 94 \\
\hline $\begin{array}{l}\text { Eicosapentaenoic } \\
\text { acidb }^{b}\end{array}$ & 0.992 & 90 & 0.993 & 92 & 0.995 & 95 & 0.996 & 96 \\
\hline Tocopherolb & 0.990 & 88 & 0.990 & 89 & 0.997 & 93 & 0.997 & 94 \\
\hline Seleniumb & 0.984 & 85 & 0.984 & 86 & 0.996 & 93 & 0.995 & 94 \\
\hline$\beta$-carotene ${ }^{b}$ & 0.998 & 96 & 0.997 & 95 & 0.988 & 91 & 0.981 & 89 \\
\hline Ascorbic acidb & 0.996 & 94 & 0.993 & 93 & 0.998 & 96 & 0.998 & 95 \\
\hline Dietary fibre & 0.996 & 94 & 0.992 & 93 & 0.999 & 97 & 0.999 & 97 \\
\hline $\mathrm{BI} 2 \mathrm{~b}$ & 0.995 & 90 & 0.996 & 92 & 0.991 & 93 & 0.996 & 95 \\
\hline
\end{tabular}

a Unadjusted benergy-adjusted (residual method)

Table 4: Correspondence between the original data and test data when using "Fewer sets of portion size photos" and "No individual recipes": Pearson correlation coefficients $(r)$, and percent agreement $(\%)$ in cross-classification, of selected nutrientsa $(n=156)$.

\begin{tabular}{lcccc}
\hline Nutrient & \multicolumn{2}{l}{ Fewer sets of portion size photos } & No individual recipes \\
\hline & $r$ & $\%$ & $r$ & $\%$ \\
Linoleic acid & 0.984 & 85 & 0.999 & 99 \\
$\alpha$ linolenic acid & 0.984 & 86 & 0.999 & 98 \\
Eicosapentaenoic acid & 0.976 & 88 & 0.999 & 98 \\
Tocopherol & 0.979 & 78 & 0.999 & 97 \\
$\beta$-carotene & 0.956 & 74 & 0.995 & 98 \\
Ascorbic acid & 0.978 & 84 & 0.999 & 98 \\
Dietary fibre & 0.988 & 89 & 0.999 & 99 \\
Bl2 & 0.986 & 82 & 0.997 & 95 \\
\hline
\end{tabular}

a Energy-adjusted (residual method)

tory questionnaire, or to coding of reported beverages in the menu book. There were no changes in the information given to participants on their first visit to the screening centre, nor was the menu book or diet history questionnaire changed in layout, number of questions, or in any other way. Taken together the time allocated to each interview was reduced from 75 minutes to 45 or 60 minutes, depending on logistics at the screening centre.

\section{Implications}

It is not uncommon that large-scale studies modify methods over time. For instance, the well-known Nurses Health Study has expanded its food frequency questionnaire (FFQ) several times. A 61-item FFQ was used in 1982, when dietary data collection first was implemented [23]. However, a 121-item and a 134-item FFQ have been used in later follow up studies [30,31]. As pointed out by Block, a FFQ should be validated in a population with the same age and sex distribution as the study population. If modifications are made, the ideal procedure is to validate the modified method together with the original in a new validation study [32].

All method development and tests described in this paper were carefully monitored, based on experiential knowledge, and supplemented with empirical data. The study design was under strict control and the tests illustrate the ideal situation. However, "in the real world" a number of other factors would also influence the effects of the method change. Most of these were not possible to examine before the change of data handling. For instance, the effect of the new coding rules when implemented in total was 
Table 5: Samples selected for Study II in order to compare observed intakes before and after alteration of dietary data collection routines.

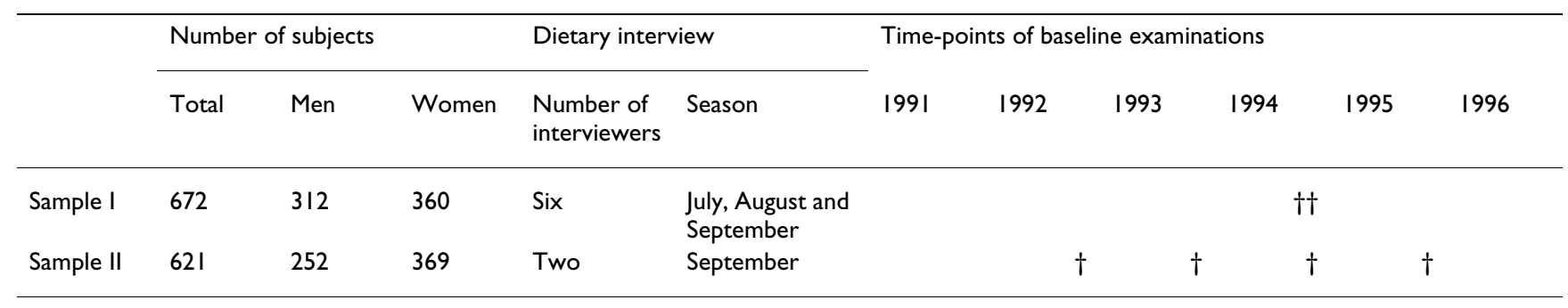

not examined. It is also possible that the dietary interviewer's decisions on choice of codes were influenced in ways not predicted. In addition, the introduction of new routines was preceded by intensified training sessions, which possibly could influence the dietary interviewers to follow all rules more consistently. Long interviewing experience could have had the opposite effect. In addition, the shorter interview time could potentially produce unintended influences on the complex interview. Both the participants and the interviewers might for instance experience the situation as more stressful. The interviewers met more participants each day and, although the number of questions asked was reduced, seeing more individuals could be perceived as an added burden. Many participants wanted to talk about details in recipes and food choices. With the reduced interview time and simplified coding procedures, there was neither time nor need for details, which could have been negatively perceived by the participants. In addition, it is possible that the shorter interview had non-intended influences on the check-up of diet history questionnaires.

In summary, the tests indicated that a change of dietary data handling routines potentially was possible without major effects on ranking of individuals on dietary intakes. However, the tests could not fully evaluate the impact of the change in dietary data handling. Such an evaluation was only possible after implementing the altered routines in the "real world" setting.

\section{Study II: Comparison of intakes estimated be- fore and after routine change Methods}

Study II is a post hoc study that uses data from the MDC baseline examinations, and examines observed mean intakes before and after change in routines.

\section{Study-samples}

Study II uses of two samples selected from the MDC cohort to include individuals joining the study before and after the alteration of interview routines (i.e., the original routines were in use until August 31 1994, and the new routines started on September 1 1994. Also, see Table 5). A study design with paired comparisons (i.e., data collected with both methods in the same individuals) was not possible. One sample included 672 individuals who joined the study in July and August 1994 (i.e., just before the alteration) and in September 1994 (i.e., right after the alteration). The other sample, selected to avoid seasonal influences, consisted of 621 individuals who joined the study in the month of September during four consecutive years (i.e., 1992 and 1993 before the alteration, 1994 and 1995 after the alteration).

\section{Variables}

Method version

A dichotomous method variable was constructed in each of the two data sets. Individuals that joined the study before September 11994 were categorised as "One", and those that joined in September 1994 or later as "Two".

\section{Dietary interviewer}

The two samples were selected with regard to interview month and year, but without specifying any particular dietary interviewer. As a result, study-participants were not uniformly distributed across the six dietary interviewers and the two method versions of sample I. However, participants belonging to sample II were interviewed by two dietary interviewers only (i.e., those that interviewed a sufficient number of participants for all four study periods), and were evenly distributed across both dietary interviewers and method versions.

\section{Food groups, energy and nutrients}

The method development and tests before alteration of routines indicated that the menu book contributed about 30 percent of the intake information for most nutrients, but for some nutrients, more than $50 \%$ of the information came from the menu book. Therefore, this study selected eight food groups to represent foods assessed mainly through the menu book (i.e., vegetables, meat, fish and milk), or the diet history questionnaire (i.e., fruits, bread, dietary fats and cheese). Energy and nutrient variables were also selected so that both those with smaller and 
larger contributions from the menu book would be represented, that is total energy ( $\mathrm{kcal})$, total fat (g), dietary fibre (g), polyunsaturated fatty acids, PUFA (g), $\beta$-carotene $(\mathrm{mg}), \mathrm{B} 12(\mu \mathrm{g})$, selenium $(\mu \mathrm{g})$, and eicosapentaenoic acid, EPA (g).

Socio-economic, demographic and lifestyle information was in the MDC collected through a self-administrated questionnaire. The influence of age, gender, and socioeconomic status were in this study examined as covariates and cofactors in the final multivariate analysis.

Leisure time physical activity was assessed by a list of activities in the questionnaire (18 items), modified from of the Minnesota Leisure Time Physical Activity Instrument [33]. Participants were asked to report how many minutes per week on average, and for each of the four seasons, they spend on a specific activity. A physical activity score was obtained by multiplying the number of minutes for each activity with an activity-specific factor, and four category variable was defined by the participants' quartile ranking.

This study used Body Mass Index (BMI) and Waist-Hip Ratio (WHR), computed from direct measurements, as indicators of obesity. Leisure time physical activity, BMI and WHR were included as covariates in the final multivariate analysis.

\section{Statistical analysis}

The statistical package SPSS was used in all analytical procedures [34]. All continuous variables were log-trans- formed before analysis to normalise distributions. Intakes of selected food groups, energy, and nutrients were compared between the first and second method versions using the general factorial analysis of variance including twoway interactions. The relations between intakes and method versions were first examined in a gender specific fully factorial design, including dietary interviewer as a cofactor. Secondly, gender specific models using main effects designs were constructed, including dietary interviewermethod interaction terms if significant. Finally, nutrient intakes were compared between method version while simultaneously controlling for energy intake, dietary interviewer, socio-economic status, age, obesity indicators (BMI and WHR), and leisure time physical activity. In order to account for the fact that dietary interviewer represents a stochastic (random) effect, the model was also formulated as a mixed general factorial model [35]. However, the analysis indicated that the stochastic effects assumption of dietary interviewers was not valid (the estimated variance components were negative), and therefore only the fixed model analysis is reported.

\section{Results}

The short term effects of change in data collection routines involving six dietary interviewers are illustrated by comparison of intakes using sample I. As indicated in Table 6 women underestimated fish, fruits and milk with the second method version compared to the first, but both men and women overestimated dietary fats. In women, a dietary interviewer-method interaction was seen for vegetables.

Table 6: Comparison of mean food group intakes before and after change in dietary data handling routines, sample $I(n=672)^{a}$.

\begin{tabular}{|c|c|c|c|c|c|c|}
\hline \multirow[t]{3}{*}{ Food groups } & \multicolumn{4}{|c|}{ Method version } & \multirow{3}{*}{$\begin{array}{c}\text { Dietary } \\
\text { interviewer } \\
\text { P-value }\end{array}$} & \multirow{2}{*}{$\begin{array}{l}\text { Interviewer-Method } \\
\text { interaction }\end{array}$} \\
\hline & & One $n=275$ & Two $\mathrm{n}=397$ & \multirow[b]{2}{*}{ p-value } & & \\
\hline & & \multicolumn{2}{|c|}{ Adjusted means } & & & $\mathrm{p}$-value \\
\hline \multirow[t]{2}{*}{ Vegetables (gram) } & Women & 186 & 181 & 0.651 & 0.270 & 0.004 \\
\hline & Men & 179 & 173 & 0.617 & 0.728 & \\
\hline \multirow[t]{2}{*}{ Fruits (gram) } & Women & 213 & 183 & 0.019 & 0.245 & \\
\hline & Men & 175 & 148 & 0.086 & 0.530 & \\
\hline \multirow[t]{2}{*}{ Milk (gram) } & Women & 376 & 325 & 0.044 & 0.149 & \\
\hline & Men & 389 & 442 & 0.160 & 0.411 & \\
\hline \multirow[t]{2}{*}{ Cheese (gram) } & Women & 39 & 43 & 0.296 & 0.092 & \\
\hline & Men & 41 & 44 & 0.486 & 0.436 & \\
\hline \multirow[t]{2}{*}{ Dietary fats (gram) } & Women & 30 & 34 & 0.048 & 0.649 & \\
\hline & Men & 45 & 53 & 0.022 & 0.968 & \\
\hline \multirow[t]{2}{*}{ Bread (gram) } & Women & 73 & 75 & 0.740 & 0.003 & 0.053 \\
\hline & Men & 133 & 138 & 0.702 & 0.048 & \\
\hline \multirow[t]{2}{*}{ Meat (gram) } & Women & 114 & 111 & 0.547 & 0.869 & \\
\hline & Men & 162 & 166 & 0.609 & $0.45 \mathrm{I}$ & \\
\hline \multirow[t]{2}{*}{ Fish (gram) } & Women & 50 & 40 & 0.006 & 0.505 & \\
\hline & Men & 50 & 47 & 0.485 & 0.867 & \\
\hline
\end{tabular}

\footnotetext{
a adjusted for dietary interviewer and interviewer-method interaction
} 
In women, unadjusted energy and nutrient intakes were mostly underestimated with the second method version compared to the first, except for polyunsaturated fatty acids and $\beta$-carotene. In men, only energy, selenium, and fibre were underestimated with the second method version. Significant dietary interviewer-method interactions were seen for $\beta$-carotene and B12 in women, and for energy, fibre, and selenium in men (data not shown).

When additional variables were added to the models (Table 7) energy intakes remained significantly lower for both gender groups. However, energy-adjusted fat intakes were higher with the second method version. Intake differences remained significant with adjustments for energy, fat, selenium, and B12 in women, and for energy, fat, and fibre in men. The only dietary interviewer-method interaction that remained significant was that for differences in $\beta$-carotene in women.

Similar comparisons using sample II, which illustrate the long term effects of altered routines involving only two dietary interviewers, indicate that fruit intakes were underestimated in women with version two, but dietary fats were overestimated (Table 8). No food-group differences between method versions were seen in men, but significant dietary interviewer-method interactions were observed for cheese, dietary fats, and bread.
When examining unadjusted intakes in women, eicosapentaenoic acid, fibre, selenium, and B12 were underestimated with the second version, but no differences were seen in energy and other nutrients. In men, energy and B12 were significantly underestimated, but $\beta$-carotene was overestimated with the second version compared to the first. Significant dietary interviewer-method interactions were observed in women for eicosapentaenoic acid, and in men for energy, fat and PUFA.

When including additional variables in the models (Table 9), most differences remained significant. All dietary interviewer-method interactions disappeared, except for energy in men. Energy-adjusted fat was overestimated in both gender groups.

Thus, differences in energy-adjusted total fat estimates were consistent in both data sets. After altered interview routines energy-adjusted fat intakes were overestimated. Additional adjustment did not change these relationships, but the dietary interviewer effects and interactions were removed (Table 7 and 9). In addition, estimates of poly-unsaturated fatty acids and eicosapentaenoic acid showed some consistency in both data sets. With energy adjusted data there were no differences in poly-unsaturated fatty acid intakes in either data set. Intakes of eicosapentaenoic acid were significantly underestimated for women in both data sets without energy adjustment, but only in sample II when adjusting for energy.

Table 7: Adjusted comparisons of energya and nutrientb intakes before and after change in dietary data handling routines, sample I (n = 672).

\begin{tabular}{|c|c|c|c|c|c|c|c|}
\hline \multirow[t]{3}{*}{ Nutrients } & \multirow[t]{3}{*}{ Units } & \multicolumn{4}{|c|}{ Method version } & \multirow{3}{*}{$\begin{array}{c}\text { Dietary } \\
\text { nterviewer } \\
\text { P-value }\end{array}$} & \multirow{3}{*}{$\begin{array}{c}\text { Interviewer-Method } \\
\text { interaction } \\
\text { P-value }\end{array}$} \\
\hline & & & One $n=275$ & Two $n=397$ & \multirow[b]{2}{*}{$\mathrm{P}$-value } & & \\
\hline & & & \multicolumn{2}{|c|}{ Adjusted geometric means } & & & \\
\hline \multirow[t]{2}{*}{ Energy } & MJ (kcal) & Women & $8.79(2100)$ & $7.92(1890)$ & 0.000 & 0.092 & \\
\hline & & Men & $11.0(2620)$ & $10.3(2460)$ & 0.045 & 0.216 & 0.189 \\
\hline \multirow[t]{2}{*}{ Fat } & $g$ & Women & 79.8 & 83.2 & 0.021 & 0.229 & \\
\hline & & Men & 103.0 & 110.2 & 0.001 & 0.933 & \\
\hline \multirow[t]{2}{*}{ PUFA } & $g$ & Women & 12.3 & 12.5 & 0.625 & 0.196 & \\
\hline & & Men & 16.3 & 17.3 & 0.078 & 0.993 & \\
\hline \multirow[t]{2}{*}{ EPA } & $g$ & Women & 0.119 & 0.091 & 0.064 & 0.291 & \\
\hline & & Men & 0.130 & 0.122 & 0.607 & 0.666 & \\
\hline \multirow[t]{2}{*}{ Dietary fiber } & $g$ & Women & 17.4 & 17.2 & 0.690 & 0.082 & \\
\hline & & Men & 20.6 & 19.0 & 0.022 & 0.607 & 0.131 \\
\hline \multirow[t]{2}{*}{$\beta$-carotene } & & Women & 2.48 & 2.61 & 0.572 & 0.601 & 0.033 \\
\hline & $\mathrm{mg}$ & Men & 2.25 & 2.05 & 0.341 & 0.611 & \\
\hline \multirow[t]{2}{*}{ Selenium } & $\mu g$ & Women & 37.0 & 32.5 & 0.000 & 0.693 & \\
\hline & & Men & 41.9 & 39.0 & 0.076 & 0.867 & 0.320 \\
\hline \multirow[t]{2}{*}{$\mathrm{B} 12$} & $\mu g$ & Women & 6.08 & 5.32 & 0.038 & 0.349 & 0.108 \\
\hline & & Men & 6.64 & 6.53 & 0.784 & 0.178 & \\
\hline
\end{tabular}

a adjusted for dietary interviewer, age, leisure time physical activity, SEI, BMI, WHR b adjusted for dietary interviewer, energy, age, leisure time physical activity, SEI, BMI, WHR 
Table 8: Comparison of mean food group intakes before and after change in dietary data handling routines, sample II $(n=62 \mathrm{I})^{\mathrm{a}}$.

\begin{tabular}{|c|c|c|c|c|c|c|}
\hline \multirow[t]{3}{*}{ Food groups } & \multicolumn{4}{|c|}{ Method version } & \multirow{3}{*}{$\begin{array}{l}\text { Dietary } \\
\text { interviewer } \\
\text { p-value }\end{array}$} & \multirow{3}{*}{$\begin{array}{c}\text { Interviewer-Methoc } \\
\text { interaction } \\
\text { p-value }\end{array}$} \\
\hline & & One $n=259$ & Two $n=362$ & \multirow{3}{*}{$\begin{array}{c}\text { P-value } \\
0.422\end{array}$} & & \\
\hline & & \multicolumn{2}{|c|}{ Adjusted means } & & & \\
\hline \multirow[t]{2}{*}{ Vegetables (gram) } & Women & 191 & 182 & & 0.164 & \\
\hline & Men & 178 & 178 & 0.989 & 0.069 & \\
\hline \multirow[t]{2}{*}{ Fruits (gram) } & Women & 227 & 196 & 0.031 & 0.563 & \\
\hline & Men & 167 & 163 & 0.758 & 0.652 & \\
\hline \multirow[t]{2}{*}{ Milk (gram) } & Women & 348 & 335 & 0.577 & 0.532 & \\
\hline & Men & 390 & 406 & 0.658 & 0.080 & \\
\hline \multirow[t]{2}{*}{ Cheese (gram) } & Women & 39 & 44 & 0.217 & 0.201 & \\
\hline & Men & 42 & 38 & 0.463 & 0.402 & 0.010 \\
\hline \multirow[t]{2}{*}{ Dietary fats (gram) } & Women & 32 & 37 & 0.029 & 0.240 & \\
\hline & Men & 47 & 49 & 0.587 & 0.865 & 0.029 \\
\hline \multirow[t]{2}{*}{ Bread (gram) } & Women & 78 & 76 & 0.642 & 0.692 & \\
\hline & Men & 124 & 129 & 0.681 & 0.123 & 0.035 \\
\hline \multirow[t]{2}{*}{ Meat (gram) } & Women & 111 & 116 & 0.337 & 0.500 & \\
\hline & Men & 164 & 164 & 0.982 & 0.160 & \\
\hline \multirow[t]{2}{*}{ Fish (gram) } & Women & 42 & 39 & 0.361 & 0.583 & \\
\hline & Men & 45 & 51 & 0.222 & 0.628 & \\
\hline
\end{tabular}

a adjusted for dietary interviewer and interviewer-method interaction

Table 9: Adjusted comparisons of energy ${ }^{a}$ and nutrient ${ }^{b}$ intakes before and after change in dietary data handling routines, sample II ( $n$ $=621$ ).

\begin{tabular}{|c|c|c|c|c|c|c|c|}
\hline \multirow[t]{3}{*}{ Nutrients } & \multirow[t]{3}{*}{ Units } & \multicolumn{4}{|c|}{ Method version } & \multirow{3}{*}{$\begin{array}{c}\text { Dietary } \\
\text { interviewer } \\
\text { P-value }\end{array}$} & \multirow{3}{*}{$\begin{array}{c}\text { Interviewer-Method } \\
\text { interaction } \\
\text { p-value }\end{array}$} \\
\hline & & & One $n=259$ & Two $n=362$ & \multirow[b]{2}{*}{$\mathrm{P}$-value } & & \\
\hline & & & \multicolumn{2}{|c|}{ Adjusted geometric means } & & & \\
\hline \multirow[t]{2}{*}{ Energy } & MJ (kcal) & Women & $8.55(2040)$ & $8.30(1980)$ & 0.268 & 0.096 & \\
\hline & & Men & $10.7(2550)$ & $10.3(2490)$ & 0.046 & 0.193 & 0.046 \\
\hline \multirow[t]{2}{*}{ Fat } & $g$ & Women & 82.3 & 85.3 & 0.004 & 0.592 & \\
\hline & & Men & 105.0 & 110.4 & 0.030 & 0.143 & 0.861 \\
\hline \multirow[t]{2}{*}{ PUFA } & $g$ & Women & 12.4 & 12.6 & 0.694 & 0.849 & \\
\hline & & Men & 16.2 & 17.3 & 0.067 & 0.682 & 0.108 \\
\hline \multirow[t]{2}{*}{ EPA } & $g$ & Women & 0.121 & 0.085 & 0.002 & 0.513 & 0.158 \\
\hline & & Men & 0.144 & 0.137 & 0.754 & 0.953 & \\
\hline \multirow[t]{2}{*}{ Dietary fibre } & $g$ & Women & 19.1 & 16.9 & 0.000 & 0.035 & \\
\hline & & Men & 20.3 & 19.9 & 0.527 & 0.538 & \\
\hline \multirow[t]{2}{*}{$\beta$-carotene } & & Women & 2.80 & 2.79 & 0.971 & 0.318 & \\
\hline & $\mathrm{mg}$ & Men & 1.91 & 2.39 & 0.031 & 0.206 & \\
\hline \multirow[t]{2}{*}{ Selenium } & $\mu g$ & Women & 36.4 & 32.4 & 0.000 & 0.719 & \\
\hline & & Men & 40.6 & 39.5 & 0.501 & 0.631 & \\
\hline \multirow[t]{2}{*}{$\mathrm{B} 12$} & $\mu g$ & Women & 6.03 & 5.08 & 0.001 & 0.818 & \\
\hline & & Men & 7.64 & 6.25 & 0.003 & 0.840 & \\
\hline
\end{tabular}

a adjusted for dietary interviewer, age, leisure time physical activity, SEI, BMI, WHR b adjusted for dietary interviewer, energy, age, leisure time physical activity, SEI, BMI, WHR

\section{Total variation}

Although the relations with fat appear consistent, dietary interviewer and method version explained a very small proportion of the total variation in fat intake. The Rsquared was 0.023 for women in sample I, and 0.004 for men, when the model included method version and dietary interviewer only. With additional adjustment (i.e., energy, obesity indicators, age, socio-economic status), the R-squared was 0.777 in women and 0.812 in men. The corresponding figures for sample II are 0.005 for women 
and 0.033 for men (when the model also included the dietary interviewer-method version interaction term). With additional adjustment, the R-squared was 0.804 for women in sample II and 0.773 for men. When the multivariate relation between fat intake and adjusting variables was examined, excluding method version and dietary interviewer, the R-squared was in sample I 0.773 for women and 0.806 for men. In sample II, the corresponding numbers were 0.801 for women and 0.769 for men. Thus dietary interviewer, method version and dietary interviewermethod interactions explain less than one percent of the total variation in fat intake.

In summary, after alteration of interview routines intakes of energy and several of the examined nutrients were lower, but energy-adjusted intakes of total fat appear overestimated. However, method version and dietary interviewer explained a very small proportion of the total variation of fat intake. The altered routines also appeared to affect intake estimates more in women than in men. For instance, fruits were consistently underestimated and dietary fats overestimated in women. Dietary interviewer-method interactions, contributed significantly to observed differences between method versions in several food groups and unadjusted nutrient intakes, but most of these did not remain significant in multivariate analysis. It should be noted that, due to the multitude of comparisons, some of the observed differences between method versions might be due to type I errors.

\section{Discussion}

Study II does not compare two dietary assessment methodologies, but evaluates whether two different approaches in handling of dietary data collected with the same MDC dietary history method produce similar mean intake estimates. The MDC study used a detailed dietary history method to enhance precision of dietary intake estimates. The high concurrent validity of the MDC diet history method has previously been documented $[3,36]$. Other studies, which have opted for the less costly food frequency questionnaire method appear to show weak or inconsistent results [37], and have attracted strong criticism $[28,38]$. Different types of methodologies differ greatly in details of food information and precision. A common threat to all nutrition epidemiological studies is random non-differential misclassification, because it commonly results in attenuated diet-disease relations. The source of such misclassification is often measurement "errors" in the dietary assessment process [38-42]. Systematic misclassification between population sub-groups is a serious problem in descriptive studies when mean nutrient intakes of specific population groups are estimated in order to evaluate the health status of the population. For instance, mean nutrient intakes are commonly compared with recommended daily intakes of specific nutrients. Re- gardless of choice of assessment methodology, it is essential for nutrition epidemiologists and public health nutritionists to understand the specific features of the dietary assessment process so that these can be accounted for in analysis and interpretation of results. For instance, diet history methods may not be robust to changes in the interviewer [2]. Also, the ability of individuals to estimate portion-sizes and common consumption frequencies in usual diet methods may depend on the specific assessment aid $[22,43,44]$, the interview technique $[45,46]$, or the organisation of the food list [47]. Studies also suggest that usual diet reports may be affected by diverse factors like season of data collection [48], ethnicity and education [13], degree of obesity $[7,49]$, socio-economic status [12], and the perception of societal norms [50,51].

\section{Impact of method change}

The altered routines of dietary data handling were only implemented for foods estimated with the menu book. No changes were made to the routines of the diet history questionnaire, or to coding of reported beverages in the menu book. The implemented changes in coding and portion size estimation were selected so that assessment of vegetables, of major selenium sources, of total fat and polyunsaturated fatty acids would not be compromised. There was a concern that foods (like vegetables, meat and fish) and nutrients (like $\beta$-carotene, selenium and EPA) with hypothesized importance for cancer development would be most affected. The different results observed in this study for women and men, the elevated estimates of energy-adjusted fat, and the dietary interviewer-method interactions (i.e., bread, cheese and dietary fats in men) were not expected. The findings may indicate that the individual portion sizes in version one produced estimates with higher precision in women, and that lower precision was obtained with the standardized portion-sizes of version two. In men, the two method versions may not have produced such differences in precision. This observation is supported by findings from another methodological study within the MDC, which concluded that women were better compared to men at estimating the amount of fat on bread when using photographic aids [14]. Researchers have observed that women are likely to respond differently to dietary assessment than men, although it is hard to fully conceptualise what it is about gender that cause these differences [2]. Studies imply that gender differences may be population specific [13], and depend on personal characteristics [51].

The observed differences in mean intakes estimated before and after change in routines needs to be considered in studies using MDC data to describe and compare food and nutrient intakes between population groups. For instance, when comparing mean intakes with dietary recommendations, and between population groups, erroneous 
conclusions about healthfulness of diet could be made, if method versions are not randomly distributed across intake levels and population sub-groups. Descriptive studies should consider selecting samples assessed with either method version to avoid distorted intakes. Depending on the specific research question adjustment for year and season of dietary interview, and dietary interviewer, should also be considered.

Some seasonal influences on observed intakes are expected in the MDC study. The menu book requests "current diet" information from seven consecutive days, while the questionnaire asked participants about their "usual diets" during the past year. Current diet methods (like diet records and 24-hour recalls) reflect dietary intakes on singular days, and are influenced by seasonal variation in food selection $[3,52]$. However, usual diet reports also tend to be influenced by the season of data collection [48]. This study controlled for season of data collection in the design, i.e., selecting individuals examined in the month of September during four consecutive years removed the influence of season. However, seasonal differences could be expected when comparing participants examined in the summer or early autumn with those examined during winter or early spring. Future studies therefore may need to consider seasonal adjustment in analysis.

The elevated fat estimates in relation to total energy with the second method was an unexpected finding. It is plausible that when the interview time was reduced comparatively more attention was given by dietary interviewers to fat providing foods, which resulted in an overestimation of fat relative to other macronutrients. This is illustrated by the overestimation of dietary fats and underestimation of fruits with version two. Both food groups are important energy contributors in this population. These observations could have implications for future studies of the relation between dietary fat and disease. Due to the latency period of chronic disease, it is likely that many cases will be assessed with the first version of the dietary assessment method during the early follow-up period. A greater proportion of non-cases would then erroneously be assigned to higher energy-adjusted fat intakes. If this were to happen in a study examining the relation between dietary fat and disease, the interpretation would be that dietary fat protects against disease even if there was no "true" relation. It should, however, be noted that method version explained a very limited proportion of the overall variation in fat intakes. Because method version, dietary interviewer and dietary interviewer-method version interactions accounted for less than one percent of the total variation, the impact of method change may be small in analytical studies. However, the distribution of cases and non-cases across methods version should be monitored in future an- alytical studies, and its impact on outcomes evaluated further.

\section{Limitations}

This study could only compare group mean intakes in groups of individuals participating in the MDC baseline examinations either before or after the change in methodology. The two method versions were not administrated in parallel and therefore it was not possible to compare means or ranking of estimates in the same individuals (i.e., paired comparisons). This approach probably exaggerated observed differences between method versions. It may be the major reason why the results are discrepant from those of Study I. The development work either used paired comparisons in the same individuals or dealt with recoded data. Other studies of usual diet methods have, however, found that portion size estimation have greater influence on estimated group means than on the ranking ability [4-6]. It is therefore plausible that the apparent underestimation of the second version compared to the first does not affect the ranking ability to the same degree. Since studies of diet and disease are examining the difference in risk between extreme exposure groups [3], the influence from the two method versions on ranking of nutrient intakes would be of major interest, but the design of this study did not allow for such examinations.

Another limitation is the non-random distribution of individuals and dietary interviewers across comparison groups. The multivariate analysis used both fixed and mixed models, but the results presented are those from the fixed model analysis. The overall effect of dietary interviewer appeared to be very small and the assumption of stochastic (random) effects of dietary interviewers was not valid. It can be argued that this study underestimated the overall dietary interviewer effects, because only a few dietary interviewers conducted interviews in the data sets selected for analysis. However, small differences across dietary interviewers are also an indication that the extensive efforts to standardise interview and coding had the intended effect. Regardless, dietary interviewer, and dietary interviewer-method interactions, contributed significantly to differences between method versions for food groups, and for energy and several unadjusted nutrient intakes. Most of these effects seemed to disappear either with energy-adjustment, or with additional variables included in the models. Therefore, the influence of dietary interviewers appears to depend on personal characteristic of study-participants.

\section{Overall conclusions}

Although, a change in dietary data collection routines is not recommended during the active data collection phase, reality sometimes forces such undesired changes. Findings of Study I suggest that alterations in the handling of die- 
tary data (when examined under carefully controlled situations) appear possible without substantial impact on the ranking ability or mean nutrient intake levels. However, as has been discussed, Study I could not assess the total impact of altered routines. Study II, which used "real world" data collected during the baseline examinations, examined mean dietary estimates before and after the alteration of routines. The latter study suggests that future descriptive studies using the MDC data should preferably select subsets of the population assessed with either method version to avoid distortion of observed intakes. Depending on the specific research question, adjustment in analysis for year and season of data collection, and dietary interviewer may need to be considered. However, the impact of altered interview routines on the outcome of analytical studies probably is small. Although, the impact of dietary data collection procedures on risk estimates of disease in the MDC study is not yet evaluated, Study II suggests that method version and dietary interviewer explained a very small proportion of total variation. Method version differences between cases and non-cases need, however, to be monitored.

\section{List of abbreviations}

MDC Malmö Diet and Cancer

EI/BMR Ratio of Energy Intake to Basal Metabolic Rate

BMR Basal Metabolic Rate

FAO/WHO/UNU Food and Agricultural Organization/ World Health Organization/United Nations University

SFA saturated fatty acids

MUFA monounsaturated fatty acids

PUFA polyunsaturated fatty acids

18:2 linoleic acid

18:3 linolenic acids

EPA eicosapentaenoic acid

kcal kilocalories

g grams

ug micrograms

mg milligrams

SD Standard Deviation
FFQ Food Frequency Questionnaire

BMI Body Mass Index

WHR Waist Hip Ratio

\section{Competing interests}

Competing interests: none declared.

\section{Authors' contributions}

Elisabet Wirfält, who is the main author and initiator of this paper, designed and implemented the analyses of Study II; Irene Mattisson and Ulla Johansson who were responsible for the dietary data collection of the Malmö Diet and Cancer study, designed and implemented the dietary method development described in Study I; Bo Gullberg provided analytical support and statistical advice; Peter Wallström provided constructive advice; Göran Berglund is the principal investigator of the Malmö Diet and Cancer Study.

\section{Appendix I. List of dishes/foods included in dif- ferent test Standard portion-sizes}

The effect of standard portion size was first analysed separately for each of the four groups, and then the effect of all groups was estimated.

Group 1: Pickled vegetables, boiled legumes, salads as main dish, shellfish, smoked fish, black-pudding/black sausage, fried potato dishes, egg dishes, porridge, pasta sauce, fast food, cakes, dressing, condiments, smoked meat, gratin/pudding, soufflé, pizza.

Group 2: Corn on the cob, tomato (preserved), artichoke, garlic, avocado, tomato, sweet pepper, onion/leek, dill/ parsley/chive, salads with mayonnaise (as side dish), fried vegetables, pickled herring, bacon, spareribs, pork bone, chicken, liver, pigs trotters, snails, cold sauces, stewed macaroni.

\section{Group 3:Desserts}

Group 4: Rice, pasta, mashed potatoes, French fries, fried potatoes, mashed turnips.

\section{Simplified coding}

The effect of simplified coding was first analysed separately for each of the six groups, and then the effect of all groups was estimated.

Group1 (included dishes giving $<1$ percent of energy and key nutrients): Fried vegetables, baked vegetables, deep fried vegetables, deep fried fish, deep fried meat, smoked meat/poultry, boiled poultry, fried black sausage, fried 
potato dishes, porridge, pasta sauce, pie, pate/mousse, crepes, pirogues, pizza, miscellaneous small dishes.

Group 2: Desserts, puddings, gratins, complete dishes, salad as main dish.

\section{Group 3: Sauces}

Group 4: Soups

Group 5: Casseroles

Group 6: Minced meat dishes (if not already tested in group 1-5)

\section{Acknowledgements}

The authors wish to acknowledge the funding support received from the Swedish Cancer Society, the Swedish Medical Research Council, the European Commission, and the City of Malmö.

\section{References}

I. Dwyer JT Assessment of dietary intake. In: odern nutrition in health and disease (Edited by: Shils ME, Olson JA, Shike M) Philadelphia, Lea \& Febiger 1994, 842-860

2. Margetts BM and Nelson M Design Concepts in Nutritional Epidemiology. Oxford New York Tokyo, Oxford University Press Oxford Medical Publications 1997,

3. Willett W Nutritional Epidemiology. Monographs in Epidemiology and Biostatistics New York Oxford, Oxford University Press 1998, 30:101147

4. Flegal KM and Larkin FA Partitioning Macronutrient Intake Estimates from a Food Frequency Questionnaire. Am J Epidemiol 1990, I31:1046-1058

5. Flegal KM, Larkin FA, Metzner HL, Thompson FE and Guire KE Counting Calories: Partitioning Energy Intake Estimates from a Food Frequency Questionnaire. Am J Epidemiol 1988, I 28:749-760

6. Hunter DJ, Sampson L, Stampfer MJ, Colditz GA, Rosner B and Willett WC Variability in portion sizes of commonly consumed foods among a population of women in the United States. Am J Epidemiol 1988, 127:1240-1249

7. Braam LA, Ocké MC, Bueno-de-Mesquita HB and Seidell JC Determinants of obesity-related underreporting of energy intake. Am J Epidemiol 1998, I 47:1081-1086

8. Lafay L, Basdevant A, Charles M, Vray M, Balkau B, Borys JM, Eschwège $E$ and Romon $M$ Determinants and nature of dietary underreporting in a free-living population:the Fleurbaix Laventie Ville Santé (FLVS) study. Int J Obes Relat Metab Disord |997, 2 1:567-573

9. Willett WC and Stampfer MJ Total energy intake: Implications for epidemiologic analysis. Am J Epidemiol 1986, I 24: I 7-27

10. Pryer JA, Vrijheid M, Nichols R, Kiggins $M$ and Elliott $P$ Who are the "Low Energy Reporters" in the Dietary and Nutritional Survey of British Adults? Int J Epidemiol 1997, 26: I46- I54

II. Klesges RC, Eck LH and Ray JW Who underreports dietary intake in a dietary recall? Evidence from the second National Health and Nutrition Examination Survey.J Consult Clin Psychol 1995, 63:438-444

12. Stallone DD, Brunner EJ and Bingham S Dietary Assessment in Whitehall II: The influence of reporting bias on apparent socioeconomic variation in nutrient intakes. Eur J Clin Nutr 1997, II:I-II

13. Liu K, Slattery M, Jacobs D, Cutter D, Mcdonald A, Van Horn L, Hilner J, Caan B, Bragg $C$ and Dyer $A$ A study of the reliability and comparability of the CARDIA dietary history. Ethn Dis 1994, 4:15-27

14. Wirfält AKE, Pettersson U, Andrén C and Mattisson I Fat on bread: An evaluation of photographic aids in portionsize estimation. Eur J Clin Nutr 1998, 52(Supplement 2):S30
15. Helsing $E$ Trends in fat consumption in Europe and their influence on the Mediterranean diet. Eur J Clin Nutr 1993, 47:S4-SI2

16. Senauer B, Asp E and Kinsey J Food trends and the changing consumer. St. Paul MN, Eagan Press I993,

17. Kromhout D, de Lezenne-Coulander C, Obermann de Boer GL, van Kampen Donker M, Goddijn E and Bloemberg BP Changes in food and nutrient intake in middle-aged men from 1960 to 1985 (the Zutphen Study). Am J Clin Nutr 1990, 5 I: I 23-I29

18. Mullenbach V, Kushi LH, Jacobson C, Gomez-Martin O, Prineas RJ, Roth-Yousey $L$ and Sinaiko A Comparison of 3-day food record and 24-hour recall by telephone for dietary evaluation in adolescencents. J Am Dietet Assoc 1992, 92:743-745

19. Fanelli MT and Stevenhagen KJ Consistency of energy and nutrient intakes of older adults: 24-hour recall vs. I-day food record. J Am Dietet Assoc 1986, 86:665-667

20. Goldberg GR, Black AE, Jebb SA, Cole TJ, Murgatroyd PR, Coward WA and Prentice A Critical evaluation of energy intake data using fundamental principles of energy physiology: I. Derivation of cut-off limits to identify under-recording. Eur J Clin Nutr |99|, 45:569-58|

21. Mertz W, Tsui JC, Judd JT, Reiser S, Hallfrisch J, Morris ER, Steele P and Lashley $E$ What are people really eating? The relation between energy intake derived from estimated diet records and intake determined to maintain body weight. Am J Clin Nutr |99|, 54:29|-295

22. Wolk A, Bergström R, Adami H-O, Ohlander E-M, Bruce Å, Holmberg $L$ and Bergkvist $L$ Self-administered food frequency questionnaire:the effect of different designs on food and nutrient intake estimates. Int J Epidemiol 1994, 23:570-576

23. Mahalko JR, Johnson L-AK, Gallagher SK and Milne DB Comparison of dietary histories and seven-day food records in a nutritional assessment of older adults. Am J Clin Nutr 1985, 42:542-553

24. Madden JP, Goodman SJ and Guthrie HA Validity of the 24-hour recall. Analysis of data obtained from elderly subjects. $J \mathrm{Am}$ Dietet Assoc 1976, 68: 143-147

25. Carter RL, Sharbaugh CO and Stapell CA Reliability and validity of the 24-hour recall. J Am Dietet Assoc 1981, 79:542-547

26. Gersovitz M, Madden JP and Smiciklas-Wright $H$ Validity of the 24hr. dietary recall and seven-day record of group comparisons. J Am Dietet Assoc 1978, 73:48-55

27. Fries E, Green $P$ and Bowen DJ What did I eat yesterday? Determinants of accuracy in 24-hour food memories. App Cogn Psychol 1995, 9:143-155

28. Sempos CT Invited Commentary: some limitations of semiquantitative food frequency questionnaires. Am J Epidemiol 1992, I 35: I I 27-I I32

29. WCRF/AICR and Potter JD Food, Nutrition and the Prevention of Cancer:a Global Perspective. Washington DC, World Cancer Research Fund/American Insitute for Cancer Research 1997,

30. Mullen BJ, Krantzler NJ, Grivetti LE, Schutz HG and Meiselman HL Validity of a food frequency questionnaire for the determination of individual food intake. Am J Clin Nutr 1984, 39: I36-I43

31. Gibson RS Sources of error and variability in dietary assessment methods: A review. J Can Dietet Assoc 1987, 48: I50-155

32. Livingstone MB Assessment of food intakes: are we measuring what people eat? Br J Biomed Sci 1995, 52:58-67

33. Taylor HL, Jacobs DR Jr, Schucker B, Knudsen J, Leon AS and Debacker $G$ A questionnaire for the assessment of leisure time physical activities. J Chronic Dis 1978, 3 I:741-755

34. Norusis MJ SPSS for Windows Professional Statistics Release 6.0. Chicago IL, SPSS Inc 1993,

35. Montgomery DC Design and analysis of experiments New York, John Wiley \& Sons 1991,

36. Riboli E, Elmståhl S, Saracci R, Gullberg B and Lindgärde F The Malmö Food Study: Validity of Two Dietary Assessment Methods for Measuring Nutrient Intake. Int J Epidemiol 1997, 26:SI6I-SI73

37. Boyd NF, Martin M, Noffel GA, Lockwood GA and Trichler DL A meta-analysis of studies of dietary fat and breast cancer risk. BrJ Cancer 1993, 68:627-636

38. Prentice RL Measurement Error and Results From analytic Epidemiology: Dietary Fat and Breast Cancer. J Natl Cancer Inst 1996, 88: I738-1747

39. Beaton GH Approaches to analysis of dietary data: relationship between planned anlysis and choice of methodology. Am J Clin Nutr 1994, 59(suppl):253S-26IS 
40. Liu K, Stamler J, Dyer A, McKeever J and McKeever P Statistical Methods to Assess and Minimize the Role of Intra-Individual Variability in Obscuring the Relationship Between Dietary Lipids and Serum Cholesterol. J Chronic Dis 1978, 3 I:399-4I 8

4I. Beaton $\mathrm{GH}$, Burema J and Ritenbaugh C Errors in the interpretation of dietary assessments. Am J Clin Nutr 1997, 65(suppl): I I00S-I I07S

42. Freedman LS Challenges for statistical approaches to dietary assessment. Eur J Clin Nutr 1998, 52:S6

43. Nelson M, Atkinson M and Darbyshire S Food photography II: Use of food photographs for estimating portion size and the nutrient content of meals. Br J Nutr 1996, 76:3 I-49

44. Schwartz N, Bless $H$, Bohner $G$ and Harlacher $U$ Response scales as frames of reference:the impact of frequency range on diagnostic judgements. Appl Cogn Psychol I99I, 5:37-49

45. Fischer RP and Quigley KL Applying Cognitive Theory in Public Health Investigations: Enhancing Food Recall with the Cognitive Interview. In Questions about questions. Inquiries into the cognitive basis of surveys (Edited by: Tanur JM) New York, Russel Sage Foundation 1992, 154-169

46. Ervin RB and Smiciklas-Wright $H$ Using encoding and retrieval strategies to improve 24-hour dietary recalls among older adults. I Am Diet Assoc 1998, 98:989-994

47. Boutron MC, Faivre J, Milan C, Lorcerie B and Esteve J A comparison of two diet history questionnaires that measure usual food intake. Nutr Cancer 1989, I 2:83-9 I

48. Subar AF, Frey CM, Harlan LC and Kahle L Differences in Reported Food Frequency by Season of Quetionnaire Administration: The 1987 National Health Interview Survey. Epidemiology 1994, 5:226-233

49. Johansson L, Solvoll K, Björneboe G-EA and Drevon CA Under-and overreporting of energy intake related to weight status and lifestyle in a nationwide sample. Am J Clin Nutr 1998, 68:266-274

50. Kromhout $D$ and Bloemberg BPM Methods in nutritional epidemiology. In Coronary Heart Disease Epidemiology From Aetiology to Public Health Oxford New York Toronto Melbourne, Oxford University Press |992, |40-I5|

5I. Hebert JR, Yunsheng M, Clemow L, Ockene IS, Saperia G, Stanek EJ III, Merriman P and Ockene / Gender differences in social desirability and social approval bias in dietary self-report. Am J Epidemiol 1997, 146:1046-1055

52. Hartman AM, Brown CC, Palmgren J, Pietinen P, Verkasalo M, Myer $D$ and Virtamo J Variability in Nutrient and Food Intakes Among Older Middle-Aged Men. Am J Epidemiol 1990, 132:9991012

Publish with Biomed Central and every scientist can read your work free of charge

"BioMed Central will be the most significant development for disseminating the results of biomedical research in our lifetime. "

Sir Paul Nurse, Cancer Research UK

Your research papers will be:

- available free of charge to the entire biomedical community

- peer reviewed and published immediately upon acceptance

- cited in PubMed and archived on PubMed Central

- yours - you keep the copyright

Submit your manuscript here:

http://www.biomedcentral.com/info/publishing_adv.asp
BioMedcentral 